\title{
O GÊNERO PUBLICITÁRIO E O EMPODERAMENTO FEMININO NA PERSPECTIVA DO DIALOGISMO BAKHTINIANO
}

\author{
ADVERTISING GENDER AND FEMALE EMPOWERMENT FROM THE \\ PERSPECTIVE OF BAKHTIN DIALOGISM
}

Recebido: 27/10/2021

\author{
Aprovado: 15/12/2021
}

Publicado: 22/12/2021

DOI: $10.18817 /$ rlj.v5i2.2694

Cellyane Sousa Negreiros ${ }^{1}$

Orcid ID: $\frac{\text { https://orcid.org/0000-0002-9938-7107 }}{\text { José Domingos }}{ }^{2}$

Orcid ID: https://orcid.org/0000-0003-2765-1009

Resumo: Este artigo apresenta como objetivo analisar o discurso produzido por propagandas de cunho feministas na mídia brasileira. Partindo do conceito de dialogismo em Bakhtin (2006), a pesquisa procurou estabelecer, por meio de propagandas destinadas ao público feminino, como se materializa a discussão do empoderamento feminino. Para tanto, partimos dos discursos que aparecem nas Revistas Vogue Brasileira e Avon, considerando o modo como a construção discursiva sobre o empoderamento feminino é apresentada nessas revistas. Trata-se de uma pesquisa bibliográfica, com abordagem qualitativa. Os resultados mostraram que a Vogue enuncia a partir dos estereótipos de beleza internalizados na sociedade, e, assim, a relação dialógica se estabelece através de uma discursividade que procura reproduzir os padrões vigentes no meio social sobre a mulher. Já a Avon apresenta outras possibilidades, que podem ser percebidas no reconhecimento de novas identidades, beleza, corpo e o que de fato se pode se considerar enquanto ser mulher e o próprio ato de empoderamento. Constatamos a necessidade de se repensar o modo como essas mídias discursivizam a figura da mulher, seja por via de uma construção discursiva que reproduz um padrão de beleza estereotipado seja na circulação de dizeres sobre o empoderamento, quando abrem espaços para discutir outras possibilidades de existência de corpos e identidades.

Palavras-chave: Dialogismo. Anúncio publicitário. Feminism. Empoderamento.

Abstract: This article aims to analyze the discourse produced by feminist advertisements in the Brazilian media. Based on the concept of dialogism in Bakhtin (2006), the research sought to establish, through advertisements aimed at the female audience, how the discussion of female empowerment is materialized. To do so, we start from the discourses that appear in Vogue Brazilian and Avon Magazines print advertising, considering the way in which the discursive construction about female empowerment is presented in these magazines. This is a bibliographical research, with a qualitative approach. The results showed that Vogue enunciates from the stereotypes of beauty internalized in society, and, thus, the dialogical relationship is established through a discursiveness that seeks to reproduce the current patterns in the social environment about women. Avon, on the other hand, presents other possibilities, which can be seen in the recognition of new identities, beauty, body and what can actually be considered as a woman and the very act of empowerment. We found the need to rethink the way in which these media discourses on the figure of women, either through a discursive construction that reproduces a stereotyped beauty pattern or in the circulation of sayings about empowerment, when they open spaces to discuss other possibilities for the existence of bodies and identities.

Keywords: Dialogism. Advertisement. Feminism. Empowerment

\section{Introdução}

\footnotetext{
1 Graduada em Letras-Português pela Universidade Estadual da Paraíba - UEPB. E-mail: cellysnegreiros@gmail.com

2 Doutor em Linguística pela Universidade Federal da Paraíba. Professor do Departamento de Letras e Artes da Universidade Estadual da Paraíba. Desenvolve pesquisas em Estudos do discurso, com interesse nas temáticas das subjetividades e relações de poder. E-mail: domingosuepb@gmail.com
} 
Refletir acerca do feminismo consiste em traçar uma análise sobre a condição feminina ao longo da história. Através desse percurso, compreende-se que a mulher sempre esteve submetida ao domínio masculino, derivado de uma sociedade alicerçada no patriarcado. Pensar sobre o movimento feminista implica também ter que discorrer a respeito do empoderamento que, por sua vez, refere-se a possibilitar à mulher a sua autoafirmação enquanto agente social, autora de sua própria história e dona de seu corpo; em outras palavras, rompendo com os paradigmas de uma sociedade baseada no patriarcalismo.

A partir desse cenário, as mídias sociais, com seus anúncios publicitários, enquanto meios de comunicação de massa, são responsáveis pela divulgação de informações para o grande público, e influenciam na formação de opinião das pessoas. Pode-se considerar que esse tipo de mídia, ao trabalhar com a imagem da mulher para a venda de cosméticos, acessórios, roupas, comerciais e campanhas das mais variadas naturezas, exerce certa influência na forma como a figura feminina é apresentada (tanto de modo positivo, quanto negativo).

Nessa perspectiva, o tema deste trabalho visa discutir a figura da mulher empoderada, feminista, no contexto dos textos publicitários, com foco nos anúncios. A problemática pela qual se guia este estudo parte da seguinte indagação: como o empoderamento feminino, em sua relação com o feminismo, é abordado nas peças publicitárias?

Para que se possa responder à questão, tem-se como objetivo geral: analisar o discurso produzido pelas propagandas de cunho feministas na mídia brasileira, considerando o olhar sobre a beleza feminina nesses anúncios. Os objetivos específicos são: 1. Identificar a construção discursiva produzida por esses anúncios à luz do dialogismo de Bakthin; e 2. Descrever as relações dialógicas entre os anúncios publicitários relacionadas à beleza e a responsabilidade social dos anunciantes.

Percebendo a importância das lutas feministas com relação ao papel da mulher na sociedade, nota-se que a figura feminina passa a ser vista através de uma nova ótica, sobretudo nos meios midiáticos. As propagandas de produtos, objetos, roupas, acessórios, bebidas, alimentos, procuram se adaptar às mudanças sociais para que o marketing de seus produtos possa agradar a todos.

A necessidade de trazer tal temática para o campo dos debates acadêmicos reside no fato de que a mídia é um espaço de reprodução de construção discursiva, 
de intensa inserção em nossas vidas, que ocorre por meio de televisão, publicidade, rádio, internet, dentre outros, tendo como objetivo condicionar o sujeito a seguir uma certa forma de pensar e, obviamente, consumir.

Assim, ao propor as análises, tem-se um ponto central para repensar formas de discursos que limitam o poder da mulher sobre o próprio corpo e história. Logo, este estudo possibilita novas percepções sobre construções discursivas, padrão de beleza, estereótipos e relações de poder sob uma ótica feminista e dialógica.

\section{Metodologia}

Com relação à natureza desse estudo, pode-se classificá-lo como uma pesquisa bibliográfica, tendo abordagem qualitativa e método dialógico discursivo. Por estudo bibliográfico compreendem-se aqueles que apresentam por base 0 levantamento de dados, através de livros, revistas, artigos, trabalhos de conclusão de curso, monografias, dissertações e qualquer material relacionado à bibliografia, conforme ponderam Lakatos e Marconi (2003).

Com relação à abordagem qualitativa, entende-se esta enquanto um tipo de pesquisa que procura analisar, discorrer e apresentar considerações acerca de certo evento social, sem a preocupação de obter resultados referentes a números, mas chegar a determinadas observações sobre o universo pesquisado. Esse tipo de estudo preocupa-se em traçar análise sobre um determinado fenômeno, procurando explicar sua natureza, realizar análises para que se possa explicar tal ocorrência, com intuito de chegar a certas considerações (LAKATOS; MARCONI, 2003).

Esse tipo de abordagem permite ao pesquisador descrever, compreender e explicar certos fenômenos. No caso desta proposta que trazemos, aborda-se a relação entre a representação da mulher, enquanto empoderada nas propagandas brasileiras, dentro da perspectiva do dialogismo bakhtiniano.

Em um primeiro momento, tem-se a apresentação dos caminhos metodológicos do estudo, explicando a abordagem usada e a forma como a pesquisa foi se construindo. Em seguida, o desenvolvimento teórico, no qual se tem um breve apanhado sobre o feminismo, em que se discute as questões políticas, sociais, históricas e culturais de tal movimento.

Ainda no desenvolvimento, aborda-se o empoderamento e as rupturas das mulheres com as relações de poder, apresentando as formas como se constroem 
essas relações e o modo como a mulher pode notar esses pontos e desconstruir-se. Também abordamos discurso e dialogismo, apresentando os conceitos de Bakhtin sobre esses dois termos e mostrando este discurso materializado na realidade concreta e nas relações sociais. Em seguida, discorremos sobre o gênero publicitário, fazendo uma explanação da publicidade enquanto construção discursiva. Por fim, vem a análise da discussão, evidenciando como ocorre o dialogismo na relação discursiva das campanhas publicitárias da Revista Vogue Brasil e Avon.

\section{Breves considerações históricas acerca do feminismo}

Desde a Antiguidade grega, filósofos como Aristóteles defendiam um pensamento de que homens eram superiores às mulheres. Através da institucionalização da família, propriedade privada e organização social, instaura-se um modelo embasado pelo patriarcalismo, no qual a figura feminina é determinada dentro de uma perspectiva doméstica, que ao longo do tempo tem se tornado cada vez mais afirmado (MENDES; VAZ; CARVALHO, 2015).

Todavia, Narvar e Koller (2006) evidenciam que, ao contrário do pensamento do filósofo grego, o movimento feminista surge como uma forma de reconhecer as individualidades e experiências vivenciadas por homens e mulheres. Entende-se nessa visão que o feminismo não diz respeito a uma mera teoria que coloca a mulher como superior ao homem. Em contrapartida, corresponde a um movimento que procura transgredir a dominação e supremacia do masculino, sobretudo, enquanto autor da história.

Partindo dessas considerações, se torna claro que o movimento chama atenção para a desconstrução dos padrões estabelecidos pela sociedade embasada pelo patriarcado. Dessa forma, abre-se um espaço para que a mulher seja reconhecida como sujeito social, capaz de desempenhar função de agentes transformadoras de meios sociais.

A partir dessa perspectiva, costuma-se dividir o processo histórico do feminismo em de três momentos ou as três ondas feministas: primeira onda, que vai do século XIX até o século XX; a segunda, correspondente aos períodos de 1960 até os anos de 80; e a terceira onda, iniciada nos anos de 1990 e durando até a contemporaneidade, conforme descreve Corrêa (2001). Cada um desses momentos 
vai apresentar uma abordagem teórica própria e questionar os valores sociais e culturais da sociedade.

O primeiro momento é o do surgimento do movimento, numa tomada de consciência por parte da mulher de que ela deveria se colocar enquanto autora de sua própria história e experiência enquanto ser humano. Destaca-se também aspectos relativos à equivalência entre os direitos civis, como fica claro nas questões ligadas às sufragistas. Considera-se que o início das lutas feministas já versava sobre questões que seriam abordadas mais adiante, nas pautas do movimento que são ligadas ao gênero, mesmo que ainda não se falasse nisso tecnicamente, necessariamente, recorrendo a essa terminologia (NARVAR; KOLLER, 2006).

De acordo com França e Ribeiro (2014), passada essa fase inicial, o movimento perde a força, por volta de 1930, reaparecendo novamente durante os anos 60, que correspondem à segunda onda do feminismo. No entanto, as ideias que precedem e incentivam essa segunda onda vem, sobretudo, do pensamento de Simone de Beauvoir e Betty Fridman. Os propósitos tanto de Beauvoir como de Fridman focavam em tecer considerações que problematizassem as formas de opressão à mulher na sociedade industrial. As autoras foram as primeiras filósofas a abrir espaços para os debates sobre gênero e sexo biológico e acreditavam que a questão central consistia na dominação do masculino, como sendo uma forma de exercer a relação de poder sobre o feminino. Assim, sobretudo Simone de Beauvoir traça a questão da desnaturalização do sexo biológico e de gênero, o que, consequentemente, acaba influenciando e ganhando espaços durante a terceira onda feminista.

É interessante perceber que as questões abordadas por Beauvoir residem no fato da construção social: ser mulher corresponderia não à existência do sexo biológico, mas sim ao processo histórico-social e cultural de um contexto, no qual a mulher tanto pode transgredi-lo quanto absorvê-lo. Em outras palavras, sexo biológico e gênero são questões diferentes para a filósofa. E essa separação foi necessária para que se pudesse pensar sobre a imposição do masculino e sua tentativa de supremacia com relação ao feminino.

Segundo Beauvoir (1967), a dominação do masculino incorpora esses padrões definidos sobre o condicionamento social através da relação entre sexo/gênero, como forma de internalizar um discurso autoritário sobre a posse do corpo feminino e seu lugar no meio social. As teorias de Beauvoir serviram de base para as discussões abarcadas também na terceira onda do Feminismo. 
Dessa forma, as questões centrais da terceira onda do Feminismo se alicerçam por meio das questões de gênero, sexo e relação de poder. As análises e questionamentos dessa fase vão de encontro a pontos em torno da diversidade, etnia, lugar de fala, questões sociais acerca das mulheres e o modo pelo qual o patriarcado foi determinando o papel da mulher durante o percurso histórico da humanidade.

Essa terceira onda apresenta como principal teórica Judith Butler, que estabelece a teoria queer e aborda aspectos em torno da relação de poder, gênero e sexo como construções sociais. De acordo com Butler (2010), gênero enquanto construção social ocorre através da performance que os corpos vão assimilando em suas vivências.

Indo mais além, Butler (2010) enfatiza que as questões de gênero e relações de poder deveriam ser incorporadas ao movimento feminista, como maneira de transgredir e repensar o papel das mulheres e seus lugares de fala dentro do meio social. Em outros termos, a autora chama atenção para demandas em torno do empoderamento feminino. Ou seja, um mecanismo pelo qual a mulher não limita sua identidade apenas para sua biologia, mas rompe com os paradigmas da sociedade como forma de marcar seu espaço no meio social.

\section{Empoderamento: a mulher se reposiciona nas relações de poder}

Tecer considerações sobre o termo empoderamento vai ao encontro de refletir sobre problemáticas de relação de poder, sobretudo quando se pensa acerca do Feminismo e da luta pelos direitos das mulheres, além dos aspectos de gênero e das questões em torno da legitimidade das identidades. Antes de adentar nas questões de empoderamento, faz-se necessário apresentar os pontos em torno do que vem a ser, de fato, uma relação de poder

Foucault ao discorrer sobre poder, relações de poder e demandas sociais, expôs que as estruturas sociais devem ser compreendidas por meio das relações de poder. Essas vão desde questões do macro até o micropoder. Para o filósofo francês, o macro diz respeito às relações que são construídas por meio da coletividade, ou seja, os sistemas econômicos, o meio de produção, a relação entre o Estado e o sujeito, a subordinação. Já o micropoder ocorre em instâncias que não são visualizadas, e acabam por se internalizarem, a tal ponto de não serem capazes de 
terem percepção pelos sujeitos nas relações sociais.

Para Foucault, o poder é tido como uma entidade, só que não enquanto uma alusão a um tipo de poder específico, mas sim enquanto uma relação construída por meio da cultura, da história, do processo de formação da humanidade. E, é dessa forma que ele se efetiva e se camufla. Logo, pode-se destacar:

\begin{abstract}
As relações de poder suscitam necessariamente, apelam a cada instante, abrem a possibilidade a uma resistência, e é porque há possibilidade de resistência e resistência real que o poder daquele que domina tenta se manter com tanto mais força, tanto maior astúcia quanto maior for a resistência. De que modo que é mais a luta perpétua emultiforme que procuro fazer aparecer do que a dominação morna e estável de um aparelho uniformizante. Em toda parte, se está em luta. (FOUCAULT, 2006, p. 232).
\end{abstract}

Estabelecendo um paralelo entre as questões de relação de poder e gênero, pode-se destacar que a submissão da mulher, assim como a subordinação feminina ao patriarcado, equivale a relações do poder que se estabelecem a partir do tipo de modelo de sociedade que o gênero dominante, e que escreveu a história, determina. Nesse caso, o homem branco, intelectualizado, com poder econômico.

Assim, compreende-se que o papel da mulher ao longo da história foi determinado pelo patriarcado, que acabou estabelecendo e naturalizando a submissão feminina com base no gênero, considerando que mulheres eram inferiores aos homens, apenas por serem mulheres. Portanto, compreende-se que 0 determinismo biológico foi usado, durante muito tempo, para explicar submissão, discriminação, violência contra a mulher, entre todas as atrocidades que o feminino sofreu ao longo do tempo.

Assim, ao procurar evidenciar o empoderamento feminino, fala-se em uma forma de ruptura contra tal dominação e relação de poder quanto ao gênero feminino. Mas, como se pode, de fato, caracterizar o empoderamento?

Como pontua Foucault (2006), sobre as relações de poder e a resistência, enfatiza-se que nesse campo o ato de se empoderar corresponderia a um processo de autoafirmação e resistência à um grupo social que determina e reproduz um discurso ideológico. Dessa forma, o empoderamento feminino se refere a ocupação dos espaços sociais, políticos e culturais, enquanto forma de se reescrever a história sob uma ótica feminina. E mais: 
O empoderamento feminino passa por vários caminhos: na sociedade, pelo conhecimento dos direitos da mulher, por sua inclusão social, instrução, profissionalização, consciência de cidadania e, também, por uma transformação no conceito que ela tem dela mesma, em sua autoestima (HEFFEL; SILVA; LONDERO, 2016, p. 7).

Empoderar, então, corresponde ao ato de tomar para si mesmo o poder. Dito de outra forma, diz respeito a questões de se conceber poder. Consequentemente, empoderamento reside no fato de conseguir transgredir uma situação de dominação na qual o poder vai sendo colocado nas mãos do próprio sujeito. Dessa forma, quando se fala em empoderamento feminino, se fala a respeito do ato/efeito de que as mulheres devem reivindicar quanto aos seus lugares de fala dentro de contexto social.

É importante também considerar que a definição de empoderamento feminino versa sobre a desconstrução dos discursos ideológicos que foram internalizados. Em outras palavras, a retomada do poder acontece de dentro para fora, a partir do momento no qual a mulher se percebe como ser reflexivo e questiona os padrões préestabelecidos em uma sociedade com resquícios do patriarcado. Esse movimento permite traçar um dialogismo, em que o reconhecimento dos discursos ideológicos deve ser desconstruído pela mulher por meio da conquista de seu lugar de fala no meio social.

\section{Discurso e dialogismo}

Bakhtin (2006), ao discorrer acerca da concepção de linguagem, apresenta o conceito de gêneros do discurso, que pode ser entendido como a construção dos enunciados que possibilitam a comunicação (tanto por meio de textos escritos quanto por produções orais), e trazem em sua composição aspectos do contexto no qual o sujeito da enunciação está inserido, ou seja, pontos em torno de dados históricos, culturais e sociais. Compreende-se que a língua, nesse contexto, apresenta uma determinada finalidade que pode ser compreendida por meio do conceito de interação verbal.

A interação verbal é colocada como sendo o que Bakhtin (2006) nomeia de realidade fundamental da língua. Entende-se esse conceito mediante uma definição de linguagem na qual ela é tomada como inerente à comunicação, no entanto, não se refere apenas a um diálogo que um sujeito trava com outrem, não correspondendo só ao exercício da comunicação enquanto forma de externar o pensamento ou 
instrumento pelo qual o sujeito se expressa.

A respeito do signo ideológico, destaca-se que ele pode distorcer uma realidade, apresentá-la de forma fiel ou, mesmo, considerá-la de um ponto de vista específico, refletindo e retratando uma ou outra realidade. O aspecto ideológico do signo linguístico deriva da enunciação concreta, em virtude disso, ela acontece através de um processo de interação social entre os sujeitos da enunciação, então, sendo marcado pelo contexto ideológico na qual o indivíduo está inserido (MOLON; VIANNA, 2012).

Outro conceito revelante no Círculo de Bakhtin é o dialogismo. Para Bakhtin (2006), tal definição se refere à relação de interação entre o que acontece entre textos, já que qualquer enunciado está ligado a outro como sendo uma reposta, e ao ponto em que ele é proferido, ele se abre para que aconteçam outras enunciações futuras. Por exemplo, na análise de um texto publicitário dentro da perspectiva do discurso dialógico, é possível apontar a relação que uma propaganda apresenta com relação a determinado assunto. Para tanto, faz-se necessário ter um conhecimento prévio acerca do discurso que esse tipo de mídia expõe em seu anúncio, através da ótica dialógica. Compreende-se enquanto dialogismo: paródias, intertextualidade, citações, referências a outro discurso, texto, etc.

O dialogismo corresponde ao modo como os discursos, por meio da enunciação e interação verbal, vão se complementando, correspondendo-se nas vozes sociais que produzem os discursos. Também é dialogismo o modo pelo qual o conhecimento está vinculado às enunciações, que se interligam por meio da interação entre os sujeitos.

Fiorin (2006) destaca que o conceito de dialogismo não é sinônimo de diálogo, no que diz respeito ao vínculo estabelecido entre os interlocutores, por exemplo. Para o pesquisador, o dialogismo consiste na relação que se estabelece entre os discursos, pois "o interlocutor só existe enquanto discurso" (FIORIN, 2006, p. 116). Dessa forma, entende-se que toda enunciação irá possuir dupla dimensão, existindo a partir de duas posições no que tange aos interlocutores.

Levando em consideração a análise de um anúncio publicitário, por exemplo, a relação dialógica funciona como o sentido que o leitor vai atribuir ao discurso que é apresentado, a partir de sua leitura do anúncio, da relação que estabelece com essa publicidade, da forma como o compreende e como o disseca; ou seja, é a relação com o enunciado que se precedem e sucedem. 
Partindo dessas questões, ao se observar um comercial de tv, por exemplo, uma campanha política, ou a leitura de um livro, seria correto afirmar que o interlocutor (nesse caso o espectador e leitor, respectivamente) vai entrar em contato com discursos de diversas naturezas, recebendo e analisando esses discursos para atribuir a eles um sentido que se configura como uma relação dialógica.

Pode-se afirmar que as relações dialógicas se dão através do entrave que pode ocorrer entre discursos diferentes - ou até mesmo discursos aparentemente iguais -. No entanto, destacamos que em Bakhtin (2006) os enunciados são únicos, dão origem aos discursos que passam a ocorrer dentro da relação de diálogo, criando assim a relação dialógica. Isso não significa compreender uma frase ou uma sentença, mas sim em entender o modo como um discurso se constitui quanto a sua atribuição de sentido - que é dada pelo outro - como também os aspectos em torno da relação que se faz a partir do contexto histórico, político, social e cultural de cada sujeito. Assim:

[...] o enunciado representa apenas um elo na cadeia complexa e contínua da comunicação discursiva, mantendo relações dialógicas com outros enunciados: ele já nasce como resposta a outros enunciados (surge com sua réplica) e mantém no seu horizonte os enunciados que o seguem (todo enunciado está orientado para a reação-resposta ativa do(s) outro(s) participante(es) da interação). (RODRIGUEES, 2004, p. 424).

O dialogismo aparece a partir da relação entre o sujeito e sua realidade, mas também nos discursos que são proferidos dentro de tal contexto. Nesse sentido, um indivíduo em uma situação comunicativa, seja a leitura de uma obra de artes plásticas, assistir um filme ou ler uma matéria de jornal, vai estar dentro de uma situação não apenas discursiva, mas também dialógica. $O$ ponto central diz respeito à atribuição de sentido e do efeito de sentido que o sujeito vai formular quanto ao discurso que lê, observa e analisa, pois, os discursos só ganham sentido no momento em que são postos diante de sujeitos sociais.

Portanto, ao entrar em contato com um texto, com um evento de comunicação, o sujeito passa a atribuir sentido, a partir do momento no qual o discurso proferido ou lido - é evidenciado. Dessa forma, a relação dialógica é, sobretudo, um processo de atribuição de sentido ao discurso de outrem, e nessa dinâmica o sujeito vai fazer uso da subjetividade, da memória coletiva, da leitura de mundo, dentre outros aspectos, para conseguir formular seu próprio discurso com relação ao que foi lido ou visto. 


\section{O gênero publicitário}

Bakhtin (2006) defende que os enunciados atendem a diversos aspectos das relações de interação entre os sujeitos, afirmando que cada enunciado é caracterizado por um gênero discursivo. Desse modo, relacionam-se com a forma pela qual acontece a interação entre os indivíduos.

Por sua vez, os discursos são formados nos enunciados que são constituídos pelos indivíduos nas interações sociais. Nesse sentido, o gênero publicitário apresenta diversas formas de construção de enunciados, que podem ocorrer no formato de comerciais de televisão, textos impressos em revistas, jornais, campanhas de moda, produtos de beleza, anúncios de internet, etc. Esses gêneros são marcados por aspectos e características que estão sempre em mudanças contínuas e visam a atingir determinado público-alvo.

Considerando, por exemplo, uma revista de cosméticos, os enunciados irão se construir para chamar a atenção do público-alvo, que nesse caso podem ser associados à figura das mulheres. A campanha da revista de cosméticos Avon, do ano de 2016, especificamente no mês de dezembro, divulgava uma linha de maquiagem na qual apareciam mulheres negras, brancas, magras, gordas, todas usando produtos da marca, apresentando um discurso de que por meio daquela linha de maquilagem elas poderiam modificar o modo como o meio social as percebia, como também aspectos em torno da autoestima, padrão de beleza, entre outros.

O texto publicitário, assim, se constrói enquanto um gênero caracterizado pelo intuito de conversar, persuadir, levar o sujeito a querer adquirir certo produto ou pensar de uma determinada forma. Para Pernambuco e Pugina (2013), o gênero denominado de texto publicitário consiste em um veículo de mídia e apresenta como intuito levar os indivíduos a serem modelados a pensar dentro de determinada forma, o que acaba influenciando também em questões de comportamento.

A propaganda é um modo específico de apresentar informações sobre um produto, marca, empresa ou instituição política ou comercial. Com o objetivo de influenciar na atitude do consumidor ou cliente, tem por princípio criar um elo entre o produtor e o consumidor. É importante ressaltar que a função essencial da propaganda é fazer conhecer um produto ou serviço, ou despertar interesse de compra/uso de produtos/serviços nos consumidores. Essa disseminação de ideias ocorre por meio da persuasão, que tem o intuito de convencer, vender, seduzir, induzir e levar a acreditar nas informações que 
são transmitidas por meio do anúncio (BAUDRILLARD apud PERNAMBUCO; PUGINA, 2002, p. 19).

Compreende-se que a função do gênero publicitário consiste em chamar a atenção de um determinado público-alvo, com intuito de levar o sujeito a sentir necessidade de possuir o produto que está sendo vendido. $O$ gênero também influencia no comportamento do indivíduo e na formação de sua opinião, já que procura convencer o consumidor de algo.

Quando se pensa, por exemplo, a relação entre o empoderamento feminino e o gênero publicitário, pode-se considerar que fundamenta-se em uma forma de chamar a atenção da mulher para problemáticas relativas à sua condição dentro do meio social. Em outras palavras, refere-se ao despertar das mulheres para que possam romper com a dominação que foram impostas a elas e o modo como são colocadas dentro de uma perspectiva social.

Dessa maneira, compreende-se que o discurso produzido pela mídia, por meio da publicidade, acaba influenciando e apresentando modos de comportamento. Quando se pensa na questão da mulher, por exemplo, a construção desses enunciados ligados a uma perspectiva de empoderamento acaba evidenciando e afirmando uma nova forma de se representar a figura feminina, assim, contribuindo para que se modifique o modo como as mulheres são percebidas no meio social.

\section{Análise e discussão}

Tendo ciência de que a publicidade é um dos principais caminhos para a divulgação de produtos, faz-se necessário compreender como ela ocorre por meio dos anúncios, sobretudo de revistas que apresentam uma gama de circulação que alcança uma variedade de públicos. No caso deste trabalho, o foco foi na relação entre a mulher, o empoderamento e os anúncios.

A Vogue é uma das mais importantes revistas de moda do mundo e tem um alcance global. Por isso, analisar os anúncios da Vogue diz respeito a entender como uma revista de moda, que trabalha com a questão da estética, representa e influencia as mulheres quanto ao empoderamento. 
Fig. 1: Editorial da Vogue - 2016

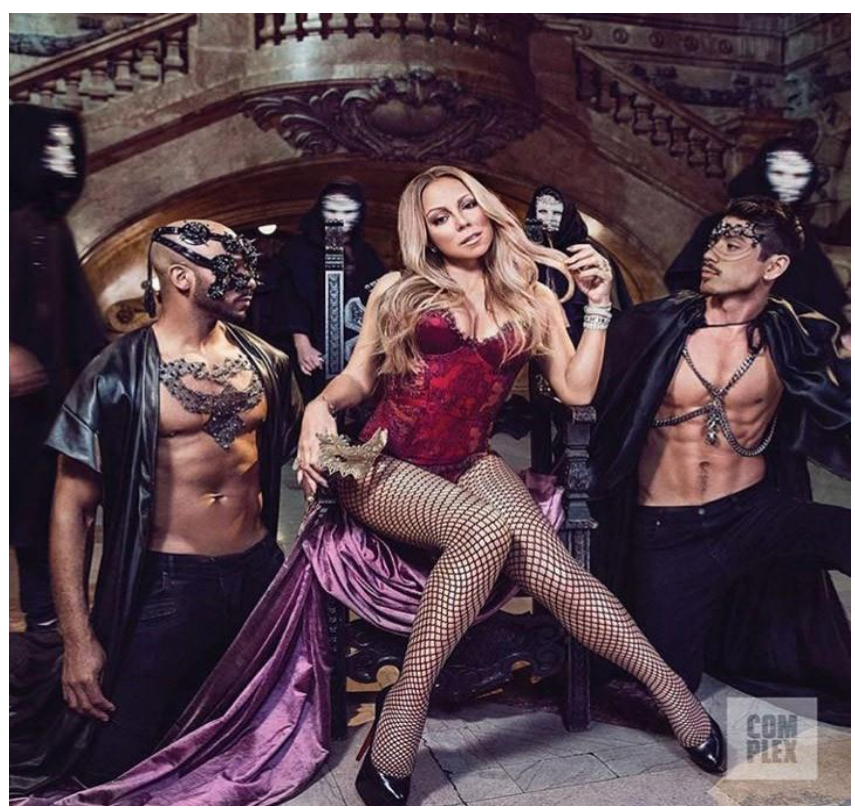

Fonte: Vogue; O globo, 2016.

A imagem 1 faz parte do editorial da revista Vogue do ano de 2016, na qual se tem a cantora Mariah Carey como modelo. Nota-se as roupas de luxo, que rementem ao consumismo, ao mesmo tempo em que a cantora encena um certo momento de tensão sexual. Poder-se-ia colocar que a questão do dialogismo de Bakhtin (2006) constrói-se na imagem como forma de demarcar o discurso que constitui na revista, que seria o da mulher Femme Fatale, a visão da mulher sedutora.

Observando a imagem 1, de imediato, é possível apontar que o editorial dialoga com o empoderamento ao ponto em que coloca a mulher como liberta dos tabus da sexualidade. No entanto, emergem outros assuntos quando se parte para uma análise aprofundada. A sexualidade da mulher deveria pertencer apenas a ela e não ser condicionada pelos homens. A imagem apresenta um discurso que se constrói pela tensão sexual, na mulher padronizada e na estética da beleza enquanto mecanismo para conseguir seduzir o homem, ou os homens. Portanto, existe uma dependência da própria sexualidade feminina como limitada ao objeto de desejo do homem. Nesse contexto, também percebemos que a mulher objetifica o homem, e isso não é feminismo.

No que diz respeito à construção dialógica, percebe-se ela justamente nesse ponto, da forma como o discurso é formulado pela Vogue e na maneira que é recebido pelo seu público-alvo. Considerando que a sexualidade pode ser vista de variadas formas, a revista limita a mulher a uma matriz de sexualidade 
heteronormativa, na qual apenas a heterossexualidade é afirmada tanto como discurso, como também relação de poder.

O dialogismo pode ser compreendido enquanto a relação que se estabelece em uma situação discursiva, na qual se tem discursos diferentes que se intercalam, segundo pondera Bakhtin (2006), e dessa forma, ao tecer uma análise sobre o empoderamento feminino como discurso e a Imagem 1, encontra-se subscrito que a possibilidade de empoderamento da mulher só seria efetivado a partir do momento em que ela aderisse à imagem estereotipada pela Vogue. Ou seja, tem-se uma ideia que evoca os velhos padrões da sexualização do corpo da mulher.

Analisar o anúncio com vista à relação dialógica de Bakhtin (2006), expõe o modo como um discurso pode ser ideológico ao ponto de determinar o que é ser e se comportar como mulher, ainda que se tenha a representação sexualidade - que no caso é usada de modo machista - partindo para uma construção social sobre "ser mulher" de uma perspectiva patriarcal, enquanto objeto de desejo do homem, apenas.

Dessa forma, pontuamos que o empoderamento - nesse caso, o falso empoderamento - apresentado pela revista vai se formulando por meio de um discurso ideológico no qual se reproduz mais uma vez a estética, beleza, sensualidade e enquadramento da mulher dentro de um molde. Como se todas as mulheres tivessem a necessidade de conquistar sua liberdade sexual apenas através de roupas de grife e padrões estereotipados, por meio dos anúncios publicitários.

É possível afirmar que não existe no anúncio analisado o rompimento com as ralações de poder. Para Foucault (2006), as relações de poder se concentram na inferiorização sutil por meio do discurso que vai sendo internalizado também de modo sutil. O anúncio de Vogue representa a crítica foucaultiana sobre como essas relações se estabelecem. Sendo o empoderamento o processo de tomar o poder para si, a imagem coloca a mulher ainda como dependente do homem, anulando a questão do empoderamento. Em vez disso, se exalta um padrão de beleza, estética de corpo, e da sexualização da mulher. 
Fig. 2: Editorial da Revista Avon - 2016

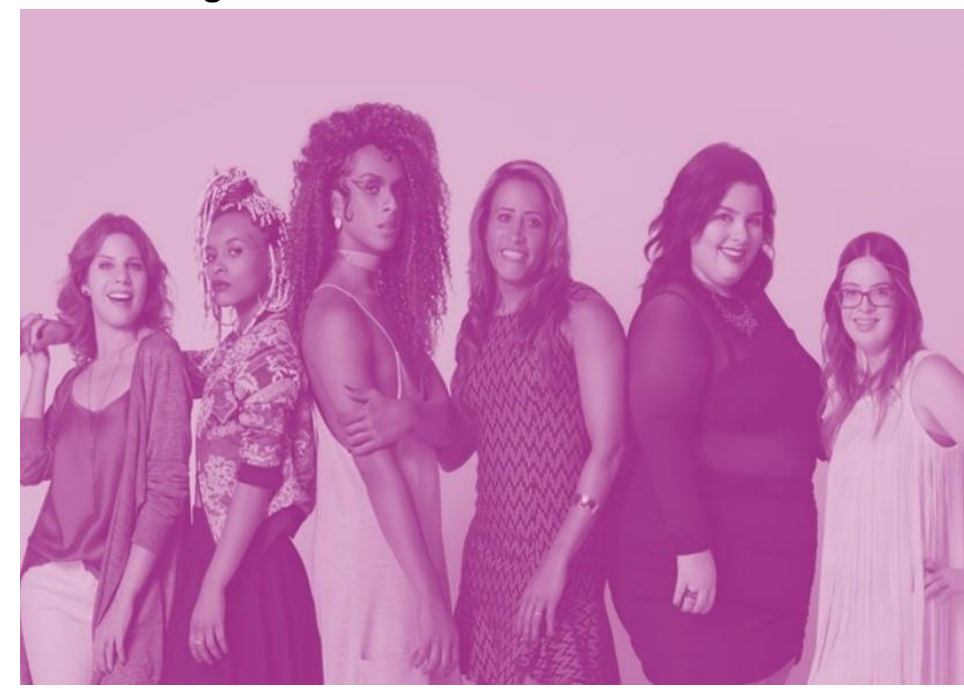

Fonte: Comunica que muda

A campanha da Avon tem como objetivo possibilitar a ruptura com as estéticas e estereótipos do corpo e isso fica perceptível na imagem 2, na qual tem-se exemplo de diversos tipos de mulheres, diversas identidades de gênero e diversos corpos. Analisando com atenção, nota-se que os corpos, assim como as identidades, são incorporadas na campanha, onde se tem Bee Reis (mulher gorda); Camomila Pri (mulher loira surda), Kessedy Kess (mulher negra e rapper), Linn da Quebrada (mulher negra e transexual), Samanta Quadrado (mulher com síndrome de down), Teresinha Guilhermina (mulher cega).

Percebe-se que, apesar de ser uma revista que vende cosméticos, o trabalho com a estética do corpo é diferente porque tem-se o elemento da ruptura com o estereótipo e a transgressão das relações de poder, assim como rompe com os discursos que promovem apenas vozes sociais e a lógica do consumo.

A relação dialógica, como aponta Bakhtin (2006), faz-se por meio dos discursos, pois o sujeito só é tal quando é posto diante de situações discursivas. Dessa forma, analisando a Imagem 2, inferimos o deslocamento do discurso da beleza e da estética - como é vista na Vogue - que ganha na Avon o processo de desconstrução, logo, abrindo espaço para a aceitação da beleza como algo único, assim como a estética dos corpos.

Então, ao passo que se pode ver na Imagem 2 corpos, estéticas, identidades diferentes quanto ao que é ser mulher, percebe-se que essas mulheres, assim como a ideia central do anúncio, rompem com padrões estereotipados e se autoafirmam enquanto sujeitos sociais. Vale a ressalva de que através da materialização do 
discurso se tem o dialogismo de Bakhtin (2006), ao se falar acerca de como a relação dialógica também ressignifica os discursos pelo sujeito social. Indo além, pode-se destacar que todas as mulheres que compõem o anúncio publicitário são mulheres que não se adequam ao discurso machista, ou seja, são mulheres que estão caminhando para a própria emancipação por meio do empoderamento, colocando-se com o que antes era doença ou patologia (gordura, cegueira, surdez, síndrome de down, transexualidade), apropriando-se de suas próprias condições para se colocarem como mulher, apenas e somente mulher.

Assim, seria correto afirmar que as mulheres representadas na propaganda da Avon apresentam o momento de ruptura com as relações de poder quanto à beleza, corpo, estética e deficiências ou "anormalidades". Dessa forma, mostrando-se que o empoderamento vai além de se pensar em termos de estereótipos, mas sim rompêlos, trazer para si o poder de se conseguir construir a própria história como também se autoafirmar como mulher empoderada ao passo que se desconstrói com as ideologias machistas.

Outro ponto que chama atenção no anúncio diz respeito ao fato de incorporar os produtos cosméticos não apenas como mercadoria, mas assimilar a eles o discurso da diversidade que se incorpora através do uso da imagem das mulheres que fazem parte da campanha. Isso chama atenção porque ao mesmo tempo que se coloca a mulher - seja qual for a categoria de análise os marcadores sobre os corpos enquanto autoras de seus discursos e autoaceitação de si mesmas, como mecanismo para se romper com o que é pré-estabelecido no meio social.

Fig. 3: Editorial da Avon - 2018

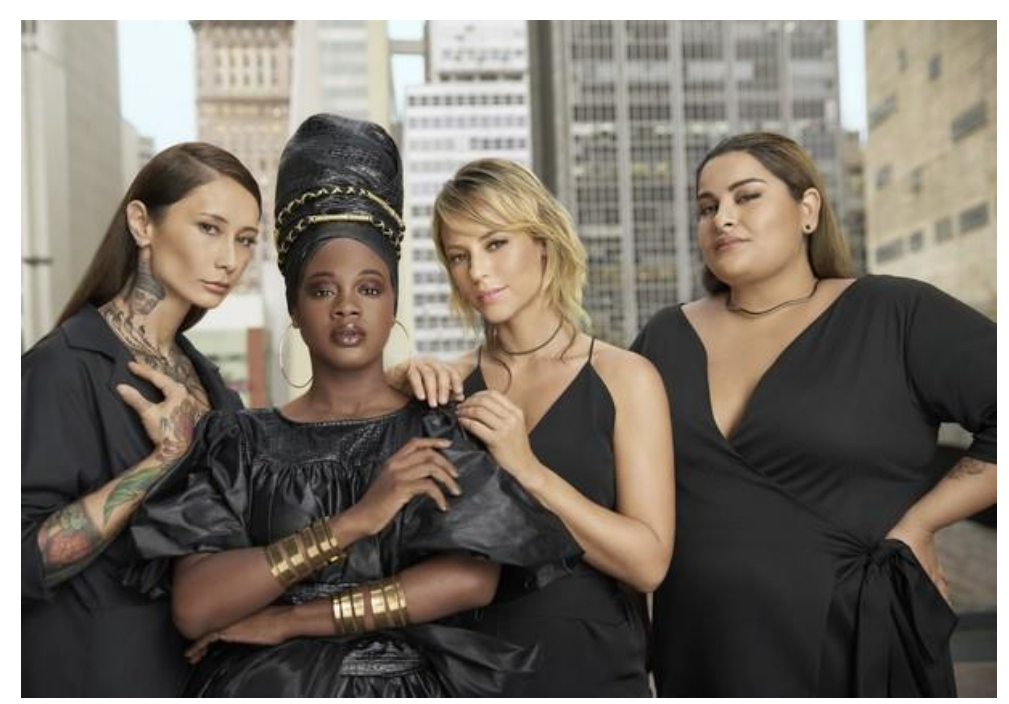

Fonte: Correios 24 horas. 
A imagem 3 faz parte da campanha de lançamento da Base Líquida True Ultramatte, da Avon. O que chama atenção na materialidade discursiva dela é a diversidade quanto à estética do corpo e da beleza. Da esquerda para a direita, podese ver nesta imagem, Akemi Higashi, Jéssica Nascimento, Paolla Oliveira e Alexandra Gurgel. Todas mulheres que apresentam uma estética própria e uma beleza própria. Mas, ainda que o anúncio se destine a vender um produto, ele acaba por englobar diferentes corpos que não são encontrados ou aceitos ao padrão de beleza convencionados por esse mercado.

Nesse sentindo, a Avon abre espaços para a discussão sobre os corpos e como se configuram a beleza não padronizada a partir da venda de um produto. Apesar da campanha apresentar mulheres como Paolla Oliveira - atriz global - que se encaixa no padrão de beleza colocado pela mídia, tem-se em contrapartida Alexandra Gurgel, que é uma mulher gorda, e que faz questão de se colocar como tal, se apropriando desse termo para desconstruir a ideia de que a mulher só pode ser bonita quando enquadrada em um padrão.

Chama a atenção também que a mulher negra, Jéssica Nascimento, marca o ponto forte do anúncio quanto ao discurso da ancestralidade, como pode ser visto no modo como ela se encontra vestida, remetendo às indumentárias das religiões de matriz africana.

Dentro desse contexto, pode-se colocar que essas mulheres, assim como as da imagem 2, além de fugir da padronização, acabam por fazer deslocamentos das relações de poder e se tornarem empoderadas, assumindo assim um discurso no qual seus corpos e suas estéticas são uma forma de reafirmar suas identidades. Outro fator que pode ser analisado é que nos anúncios da Avon a presença do homem é totalmente desnecessária, logo mais uma vez se tem a reafirmação da mulher e do empoderamento do feminino e pelo feminino, transgredindo o patriarcado, o machismo e o sexismo.

Nota-se, portanto, a relação dialógica na dinâmica enunciativa das propagandas ora analisadas. Ou seja, nessas peças publicitárias observa-se várias mulheres, com diversos corpos, belezas, idades, identidades, o que reafirma outros padrões de beleza feminina, abrindo espaço para se questionar corpo, poder e o significado de ser mulher. Nesse sentido, tem-se o empoderamento feminino como dialógico a partir do momento em que se tem a ressignificação do corpo, das estéticas, das identidades, da forma de se vestir e da liberdade. Em outros termos, a presença 
feminina diversificada nesses espaços de enunciação desloca as relações de poder no âmbito da mídia comercial e estabelece outros modos de visibilidade, de autoafirmar enquanto ser, sujeito social e agente na história das mulheres.

\section{Considerações finais}

Ao longo desse estudo, dialogou-se acerca do modo como a mulher é representada nos anúncios publicitários e o modo como essas mídias estabelecem discursos sobre a posse quanto ao corpo feminino, considerando aspectos como relações de poder, feminilidade, sexualidade, identidade de gênero. Tendo ciência de que os discursos caminham para questões dialógicas, seja em torno do imaginário coletivo, da intertextualidade e interdiscursividade, ou mesmo pela atribuição de sentido que o interlocutor constrói sobre tais discursos, notou-se o modo como o empoderamento feminino pode funcionar a partir de tais campanhas.

A perspectiva bakhtiniana já deixa claro que todo discurso é construído socialmente, dessa forma, entende-se que um anúncio publicitário, além de querer vender um produto também, determina um tipo de comportamento que deve ser seguido pelo interlocutor ou público-alvo daquela mídia. Assim, mostramos como as revistas Vogue e Avon apresentam percepções sobre o corpo feminino e sobre o que é ser mulher de modos diferentes.

Enquanto a Vogue trabalha com a padronização da mulher como apenas uma consumidora de objetos de luxo, limitando até mesmo a sexualidade, encontra-se na Avon discussões sobre a diversidade das belezas, dos corpos, da sexualidade, da identidade de gênero, do mesmo modo que a Ipanema apresenta a essa lógica. Dessa forma, o empoderamento feminino é também um discurso dialógico quanto colocado frente ao discurso que se percebe nessas mídias.

Tendo ciência de que empoderar-se diz respeito a tomar para si o poder, seja sobre o corpo, a história ou a vida, nos dois veículos de comunicação analisados percebe-se o empoderamento feminino não apenas como um discurso dialógico, mas também enquanto possibilidade de se repensar a maneira como essas mídias enxergam a mulher, seu corpo, sua história e a possibilidade de transgressão e queda do patriarcado.

O fato desses enunciadores abordarem a mulher de forma diferenciada, sobretudo com relação ao empoderamento feminino, pode ser explicado pela natureza dos produtos que são comercializados. A Vogue se destina a uma classe de 
elite, na qual o consumo se torna um discurso naturalizado, e o mesmo acontece com o padrão de beleza. Tem-se uma reprodução da mulher enquanto modelo. Já a Avon atende a um público-alvo mais popular, ou seja, mulheres que não atendem a este mesmo referencial de consumo.

Porém, mesmo lidando com consumidoras diferentes, vale questionar o modo como a Vogue entende o ideal de mulher e se esse ideal realmente existe, pois notase uma padronização quanto ao corpo, a estética e a beleza. Logo, faz-se necessário repensar a problemática dos discursos evidenciados pela revista em questão e procurar observar como tal situação pode servir enquanto objeto de padronização da mulher.

A necessidade de lançar um olhar crítico sobre esses anúncios advém, sobretudo, da percepção da mulher enquanto ser social, histórico, político, porque o dialogismo se apresenta nessas campanhas publicitárias a partir do momento em que vão de encontro ao discurso do empoderamento feminino. Será apenas que a mulher é só um sujeito consumidor de revistas? Entendemos que não! Portanto, trabalhar a figura da mulher nessas mídias vai além de vender um produto, e isso se deve ao fato de que a figura da mulher é usada como forma de estabelecer discursos.

Esses discursos tanto podem versar sobre outras possibilidades das mulheres perceberem seu próprio corpo e se dar conta da importância do empoderamento, como também limitar-se a receber discursos instituídos, que as limitam apenas ao lugar comum. Logo, o dialogismo presente nos anúncios publicitários - enquanto situações discursivas - serve como forma para que se possa repensar as estratégias midiáticas que tendem a reproduzir os discursos de classes dominantes sobre o corpo feminino ou a romperem com os mesmos e, de fato, possibilitar a mulher outras óticas quanto ao corpo, o poder a si mesma. É nesse ponto que se ressalta a importância do Empoderamento Feminino na conquista dos espaços, lugares e do próprio corpo.

\section{Referências}

BAKHTIN, M. Estética da criação verbal. São Paulo: Martins Fontes, 2006.

BEAUVOIR, S. O Segundo Sexo - a experiência vivida: tradução Sérgio Milliet. 2 ed. São Paulo: Difusão Europeia do Livro, 1967.

BUTLER, J. Problemas de gênero: feminismo e subversão da identidade: tradução de Renato Aguiar. Rio de Janeiro: Civilização Brasileira, 2010. 
CORRÊA, M. Do feminismo aos estudos de gênero no Brasil: um exemplo pessoal. Cadernos Pagu, n.16, 2001, p.13-30. Disponível em:

http://www.scielo.br/pdf/cpa/n16/n16a02.pdf. Acessado em abril de 2020

FOUCAULT, M. Poder e saber. In: M. B. Motta (Ed.), Estratégia, poder-saber.2aㅡ ed., pp. 223-240, Coleção Ditos \& Escritos, 4. Rio de Janeiro: Forense Universitária, 2006.

FRANÇA, F. F.; RIBEIRO, T. A. Simone de Beauvoir e o movimento feminista: contribuições à Educação. Anais: do III Simpósio Gênero e Políticas Públicas. 2014. Disponível em: http://www.uel.br/eventos/gpp/pages/arquivos/GT6_Tamires\%20Almeida\%20Ribeir o.pdf. Acessado em abril de 2020.

HEFFEL, C. K.; SILVA, V.; LONDERO, J. C. A construção da autonomia feminina: o empoderamento pelo capital social. In: XII Colóquio Nacional Representações de Gênero e Sexualidade. 2016. Anais: Campina Grande: Editora Realize. 2016. p.1-10. Disponível em:http://www.editorarealize.com.br/revistas/conages/trabalhos/TRABALHO_EV053 _M D1_SA8_ID1895_11052016133624.pdf. Acessado em abril de 2020.

LAKATOS, E. M.; MARCONI, M. A. Fundamentos da metodologia científica. Rio de Janeiro: Altas, 2003.

MENDES, R. S.; VAZ, B. J.; CARVALHO, A. F. O movimento feminista e a luta pelo empoeiramento da mulher. Núcleo de Estudos e Pesquisas Sobre Gênero e Direito. n.3, 2015, p.88-99. Disponível em:

http://www.periodicos.ufpb.br/ojs/index.php/ged/article/viewFile/25106/14464. Acessado em maio de 2019.

MOLON, N. D.; VIANNA, R. O círculo de Bakhtin e a linguística aplicada. Revista Bakhtiniana. v.7, n.2. 2012. p. 142-165. Disponível em:

http://www.scielo.br/pdf/bak/v7n2/10.pdf. Acessado em maio de 2020.

NARVAZ, M.G.; KOLLER, S. H. Metodologia feminista e estudos de gênero: articulando pesquisa, clínica e política. Psicologia em Estudos. v.11, n.3. 2006. Disponível em: http://www.scielo.br/scielo.php?pid=S1413$73722006000300021 \&$ script=sci_abstract\&tlng=pt. Acessado em março de 2020

PERNAMBUCO, J.; PUGINA, R. I. Leitura bakhtiniana de um texto publicitário.

Revista Cientifica de Letras. v.9, n.2. 2013. p.44-61. Disponível em:

http://publicacoes.unifran.br/index.php/dialogospertinentes/article/viewFile/777/601.

Acessado em junho de 2020.

Sites pesquisados:

COMUNICA QUE MUDA. Disponível em:< https://www.comunicaquemuda.com.br/donas-da-beleza/>. Acesso em 12 de dez. 2020.

CORREIO 24 HORAS. Disponível em: < https://www.correio24horas.com.br/noticia/nid/deusa-do-ebano-2018-estrela- 
campanha-da-avon-com-paolla-oliveira/>. Acesso em 13 dez. 2020.

VOGUE; O GLOBO, 2016. Disponível em:

https://vogue.globo.com/moda/gente/noticia/2016/07/mariah-carey-encara-cena-defetiche-em-novo-editorial.html. Acesso em 13 dez. 2020. 